\title{
Towards Adaptation of Water Resource Systems to Climatic and Socio-Economic Change
}

\author{
Enda O'Connell ${ }^{1}$
}

Received: 17 May 2017 / Accepted: 24 May 2017 /

Published online: 17 June 2017

(C) The Author(s) 2017. This article is an open access publication

\begin{abstract}
Climate change is viewed as the major threat to the security of water supplies in most parts of the world in the coming decades, and the water resources literature continues to be dominated by impact and risk assessments based on the latest climate projections from General Circulation Models (GCMs). However, the evidence for anthropogenic changes in precipitation and streamflow records continues to be elusive which, together with the known high uncertainty in GCM ensemble projections, has led to the development of risk assessment methods which are not driven exclusively by GCMs. It is argued that a baseline risk assessment should retain the assumption of climatic stationarity, and be based on the modelling of observed interannual variability as a dominant process in determining water resource system reliability, augmented where justifiable by reliable information from GCMs. However, irrespective of what the climate does in the future, globalization and socio-economic changes are the major drivers for increases in water demand and threats to water security, as exemplified by the burgeoning economies of the BRIC and MINT countries, and the large population increases and economic growth seen in many developing countries. It is suggested that more attention needs to be paid to adaptation to socio-economic change which is arguably more predictable than climatic change, based on what is already known about population and economic growth, lifestyle changes and human choices. More focus is needed on economic analyses that can inform the major investments in water use efficiency measures which can deliver the water savings needed to avert widespread water scarcity. The effectiveness of water use efficiency measures is largely determined by (a) the potential of modern information technology to achieve more efficient water resources management and water use and (b) human responses and choices in the uptake of measures. To assess the potential efficiency gains, it is argued that water resource systems modelling needs to evolve to incorporate the human dimension more explicitly, through Coupled Human and Natural Systems (CHANS) modelling. A CHANS modelling framework is outlined which incorporates agent-based
\end{abstract}

Enda O'Connell

enda.oconnell@ncl.ac.uk

1 Water Resource Systems Research Laboratory, School of Civil Engineering and Geosciences, Newcastle University, Newcastle upon Tyne, UK 
modelling to represent individual choices within the human system, and prospects for assessing the effectiveness of efficiency measures involving individual human responses are discussed.

Keywords Climate change Climatic variability Socio-economic $\cdot$ Adaptation $\cdot$ Risk Impacts . Vulnerabilty · Demand-supply gap · Real-time operational control $\cdot$ Human system $\cdot$ Agent-based modelling

\section{Introduction}

The developing water crises across the world have been well documented in a series of UN World Water Assessment Reports (WWAP 2003; 2006; 2009; 2012; 2014; 2015; 2016). Rapid population growth across Asia, Africa and Latin America, coupled with high economic growth and increasing living standards, for example, in the BRIC (Brazil, Russia, India, China) and MINT (Mexico, Indonesia, Nigeria, Turkey) countries, mean that demand is already outstripping supply in many countries, or will do so in the coming decades. Global trade and the associated water footprints are contributing to regional supply-demand imbalances, thus enhancing water scarcity as a consequence of the export of large amounts of virtual water (e.g. Dong et al. 2013), and creating a global governance challenge (Hoekstra 2011). Rampant industrial development has led to widespread pollution of some of the available water resources, making them unsuitable for use or too expensive to treat, and irreparably damaging the water environment and its dependent ecosystems. China in particular is grappling with these problems on a massive scale, an issue that is making headlines in the international press (e.g. The Economist 2013; Bateman 2014).

Against the above global water crises background, there has been a need for water resources management approaches which can address the growing demand-supply gap and also encompass the three main objectives of sustainable development: social equity, economic efficiency and environmental sustainability. Integrated Water Resources Management (IWRM) has emerged as the dominant international paradigm, and occupies a central role in the integrated and sustainable approaches to water resources management being advocated by UN Water, the Global Water Partnership and other water sector actors. Progress with country uptake of integrated approaches has recently been assessed by UNEP (2012). Among the key messages and recommendations from the survey of over 130 countries are the following:

- $80 \%$ of countries have embarked on reforms to improve the enabling environment for water resources management based on the application of integrated approaches;

- water-related risks and the competition for water resources are perceived by a majority of countries to have increased over the past 20 years;

- countries reported a gradual but positive trend in financing for water resources development and management with more diverse sources of finance, but little progress on payment for water resources services.

Other more specific findings include the following:

- domestic water supply is ranked by most countries as the highest priority for water resources management; 
- progress on water use efficiency is lagging behind other water management reforms, with less than $50 \%$ of national reforms addressing water use efficiency.

While the adoption of more integrated approaches to water resources management represents real progress, there are still issues over the sustainability of the approaches. In managing the supply-demand balance, the predominant focus among the countries surveyed still appears to be on the development of new resources, and managing demand is receiving much less attention. This inevitably increases the pressure on water resources, leading to water resource systems that are more stressed and vulnerable to natural climatic variability, anthropogenic climatic change, and socio-economic change. One consequence of this is that when major droughts occur, they are typically attributed to climate change without due consideration of the fact that the stressed systems are vulnerable to natural climate variability. Indeed, a major and largely unsolved problem is how to attribute greenhouse gas (GHG) impacts in the presence of natural climatic variability. A further aspect of the supply-driven approach is that priority is given to the higher value uses during drought periods, with lower priority given to protecting the water environment. Moreover, in river basins where resources are shared, there is the inevitable competition between countries to gain the largest possible share, which may not be an equitable share (eg Lu et al. 2014), and again, the water environment will receive the lowest priority as water scarcity builds, leading to environmental degradation.

Sustainability requires a greater focus on reducing demand in the supply-demand balance to avoid the inevitable depletion of water resources and degradation of the water environment (Gleick 2000). From the specific finding on water use efficiency reported above, it is evident that this is not receiving the required priority in more than $50 \%$ of the countries surveyed. It is therefore inevitable that water scarcity will worsen, with demand outstriping supply in many countries with high population and economic growth, unless adaptation measures are implemented more widely that constrain and reduce rampant demand.

Overarching the water crises is the looming threat of anthropogenic climate change which is believed to be the greatest threat facing Planet Earth. This threat extends naturally to water resources because of the climate driver, and the potential impacts on water scarcity. While there is no question that the planet is warming and that this will have impacts on the climate, clear evidence of impacts on drought and flood frequency and intensity in the presence of natural climatic variability remains elusive. The dominant theme in water resources research is climate model-driven assessment of the impacts of climate change, with much less attention currently paid to water use efficiency which must be addressed if sustainable water resources management is to achieved.

Against this background, a major issue is how to approach adaptation, given that water resource systems will become increasingly stressed in the future from a combination of socioeconomic pressures and climate variability/change. Firstly, there is the issue of whether to be proactive, and invest now in supply-side measures that can provide greater water security but which invite unsustainable depletion of our water resources, or to adopt a reactive or 'wait and see' approach. Making large and irreversible proactive investments in supply-side measures may not be either be affordable or environmentally sustainable. On the other hand, demand-side measures are more incremental, and have much shorter time scales for implementation. They also provide a pathway to sustainability.

In section 2, the evidence for an anthropogenic climate change signal in precipitation and streamflow records, and for nonstationarity, is reviewed, and the implications for the modelling of background natural climatic variability and anthropogenic climate change are discussed. 
'Top-down' climate change impact assessments and 'Bottom-up' risk assessments that focus on vulnerability and adaptation to climatic and socio-economic change are reviewed in section 3. The economic and technological aspects of adaptation to the emerging supply-demand imbalances are the focus of section 4 . Section 5 deals with modelling the human dimension of adaptation, followed by some conclusions in section 6 .

\section{Evidence for Climate Change Impacts on the Hydrological Cycle and Nonstationarity}

There is incontrovertible global scale evidence that the earth is warming and that greenhouse gas emissions (GHGs) are a major driver of global warming. However, while direct impacts are evident from melting ice caps, shrinking snow packs, rising sea levels, the expected impacts on precipitation and streamflow at basin scales have been much more difficult to demonstrate. There is large natural spatial and temporal variability within the climate system that is linked to various longer-term modes of variability which are driven by fluctuations in sea surface temperatures and ocean dynamics (O'Connell et al. 2016). A GHG climate change signal needs to be sufficiently strong to allow detection in the presence of significant background variability, and to justify the assumption of nonstationarity (Milly et al. 2008).

The recent IPCC Special Report on 'Managing the Risks of Extreme Events and Disasters to Advance Climate Change Adaptation' (IPCC 2012) is measured in making assessments of the available evidence for changes in climate extremes. Examples of assessment of evidence relating to rainfall, flooding and droughts are (references are to chapters for supporting evidence):

'There is medium confidence that some regions of the world have experienced more intense and longer droughts, in particular in southern Europe and West Africa, but in some regions droughts have become less frequent, less intense, or shorter, for example, in central North America and north western Australia.' [3.5.1]

'There is limited to medium evidence available to assess climate-driven observed changes in the magnitude and frequency of floods at regional scales because the available instrumental records of floods at gauge stations are limited in space and time, and because of confounding effects of changes in land use and engineering. Furthermore, there is low agreement in this evidence, and thus overall low confidence at the global scale regarding even the sign of these changes.' [3.5.2]

'Projected changes in climate extremes under different emissions scenario generally do not strongly diverge in the coming two to three decades, but these signals are relatively small compared to natural climate variability over this time frame. Even the sign of projected changes in some climate extremes over this time frame is uncertain. For projected changes by the end of the 21st century, either model uncertainty or uncertainties associated with emissions scenarios used becomes dominant, depending on the extreme.' [Summary for Policymakers]

In the IPCC Fifth Assessment Report (Hartmann et al. 2013: AR5 - WG1:Chapter 2.6: Changes in Extreme Events), the following summary of the evidence for trends in droughts is given:

'In summary, the current assessment concludes that there is not enough evidence at present to suggest more than low confidence in a global-scale observed trend in drought 
or dryness (lack of rainfall) since the middle of the 20th century due to lack of direct observations, geographical inconsistencies in the trends, and dependencies of inferred trends on the index choice. Based on updated studies, AR4 conclusions regarding global increasing trends in drought since the 1970s were probably overstated. However, it is likely that the frequency and intensity of drought has increased in the Mediterranean and West Africa and decreased in central North America and north-west Australia since 1950 '

Therefore, there is a lack of substantial evidence that GHG-induced global warming is having a detectable impact on the frequency and intensity of droughts, and therefore on water resource reliability. Drought occurrence has historically been a consequence of natural variability in the climate system, and strong interannual variability in some continental zones can result in persistent droughts that last over several years. This has been particularly evident in the case of the River Nile which first attracted the interest of a British hydrologist, H.E Hurst, who famously characterized this variability through a coefficient $\mathrm{H}$ which is a direct measure of the strength of interannual climatic variability/long-term persistence in annual rainfall, streamflow and other geophysical variables (Hurst 1951, 1956). A value of $\mathrm{H}=0.5$ corresponds to no persistence (independence); increasing levels of long-term persistence are indicated by values of $\mathrm{H}$ approaching 1 . In a review of the wide-ranging influences of Hurst's work, O'Connell et al. (2016) consider the different modes of decadal and longer time scale variations in the climate system that lead to long-term persistence and which are driven by fluctuations in sea-surface temperatures and ocean dynamics.

Natural climatic variability manifests itself in long-term records as swings, cycles and apparent trends that undergo random reversals and are of irregular length. Hurst's characterization of this long-term persistence (LTP) has led to a number of stationary stochastic models that can reproduce LTP. Many shorter climatic and hydrologic records can exhibit apparent trends which might be interpreted as evidence of GHG-induced climate change but which may be due to natural climatic variability/LTP or a mixture of both. Given the expectation that global warming should lead to trends in climatic and hydrologic time series, there has been a large upsurge in trend analyses which seek to provide the evidence for climate change. Many of these analyses fail to recognize that apparent trends may be a manifestation of natural climatic variability and LTP, as first quantified statistically by Hurst (1951), and not necessarily anthropogenic climate change. Concern has been expressed about the degree of statistical rigour associated with such analyses; Clarke (2010) has discussed four areas of concern, including the use of the same data set both to suggest a hypothesis (commonly of trend over time) and to test it. Koutsoyiannis (2003) and Cohn and Lins (2005) have demonstrated that, when testing for trends, the conventional assumption of independence for the null hypothesis can lead to an artificially high level of significance; if the more plausible assumption of LTP is made for the null hypothesis, the level of significance drops dramatically.

Nonetheless, in cases where increases in temperature associated with global warming have induced changes in seasonal snowmelt patterns, for example, the climate change signal can be quite strong. However, in the case of precipitation, there is large natural variability in space and time within the climate system, which makes the detection and attribution of GHG-driven changes a very challenging problem, as evidenced by the IPCC findings reported above. Therefore, from the current evidence, natural climatic variability represents the first order source of climatic variability that water resources management must contend with in the coming decades while still looking to climate models to provide information on what global 
warming might do to enhance this natural variability. As longer instrumental records are obtained and as paleo records are examined, the scale of natural climatic variability becomes more apparent, and that 'change is nature's way' (Koutsoyiannis 2010). Moreover, it has been shown that stationary stochastic models can be used to reproduce this variability/long-term persistence over millennial time scales (Markonis and Koutsoyiannis 2014), and that it is not necessary to reject stationarity (Koutsoyiannis and Montanari 2015).

A major challenge is the attribution of anthropogenic climate change impacts on precipitation and streamflow in the presence of natural climatic variability. Liu et al. (2012) make the salient point that many climate change impact assessment studies start from the position that impacts are attributable to GHG-induced climate change only, and do not properly account for natural climatic variability. Using seven future climate projections derived from three GCMs and three emission scenarios, the impact of future climate change on water resources was estimated in terms of separating its contribution from natural climatic variability. It was found that, for the baseline period, and for the future period from 2021 to 2051, the impact of natural climatic variability may play a major part, whereas, for the period from 2061 to 2091, anthropogenic climate change may dominate the changing process. The results highlight the importance of separating the impacts of natural climatic variability when assessing the impacts of anthropogenic climate change.

Jia et al. (2012) have demonstrated an attribution approach for the highly water-stressed Hai River Basin of China. Using a fingerprinting technique first applied in the climate science field (Hasselmann et al. 1997) in conjunction with modelling and scenario analyses, the study has attempted to attribute the observed changes of water resources availability in the basin over a 40-year period (1961-2000) to different factors including natural climate variability, GHGdriven climate change, and local human activity. The results indicate that natural climate variability and local human activity may be two factors responsible for the observed changes of water resources availability during the past 40 years in the basin, with local human activity being the main factor that accounted for about $60 \%$ of the changes.

\section{Risk-Based Assessments of Climate Change Impacts and Adaptation Measures}

The recent literature on climate change impact assessment has seen the beginning of a shift away from 'Top-down' climate model-driven assessments towards 'Bottom up' risk- based assessments that focus on vulnerability and are more location specific. Wilby and Dessai (2010) have suggested that, while General Circulation Models (GCMs) have been instrumental in showing the need for action to curb greenhouse gas emissions, they have been less helpful in informing how to adapt at regional and local scales.

Given the legacy of past emissions and the prospect of unavoidable climate change, Wilby and Dessai (2010) pose the following question: 'how can we ensure that adaptation measures realize societal benefits now, and over coming decades, despite uncertainty about climate variability and change?'

They distinguish two complimentary approaches to adaptation. 'Top-down' or scenario-led methods involve downscaling GCM climate projections under a range of emission scenarios which are then fed into impact assessment models. The vast majority of impact assessment studies stop at the assessment stage, and do not generally identify adaptation strategies or decisions; decision-making is impeded by the disparity in GCM ensemble projections. 
Moreover, they tend to focus primarily on supply-side assessments, and possibly to induce local, regional, or national 'grabs' for water from shared surface and groundwater resources to which property rights are poorly defined (Olmstead 2014). 'Bottom-up' or reactive methods focus on reducing vulnerability to past and present climate variability, typically in the wake of extreme events or disasters. The bottom-up approach reflects a focus on the factors and conditions that enable successful coping with climate at the level of individuals, households and communities.

The large volume of 'Top-down' studies, and their dominant position within the scientific evidence presented by the IPCC in their assessment reports, has inevitably created pressure for government agencies responsible for water resources and flood risk management to make proactive investments in water resources and flood risk management infrastructure. However, society cannot afford widespread implementation of this approach, particularly in times of economic stringency, and there may be associated economic regrets due to benefits foregone in other sectors. Matalas $(1997,1998)$ has suggested that the strategy of 'wait-and-see' i.e. delaying the making of important, expensive and essentially irreversible capital investments could serve water managers well in coping with the uncertainties regarding climate change. So should a proactive approach (invest now) or a reactive approach (wait and see) to investment be taken in a highly variable climate, and with a high degree of uncertainty about the future?

O'Connell and O'Donnell (2014) have used a cost-benefit approach to evaluate proactive and reactive flood defence investment strategies under increasingly variable annual maximum flood regimes generated by a stochastic model incorporating long-term persistence. It was found that, as model variability/long-term persistence increased, there was a change in investment strategy optimality from proactive to reactive. Jeuland and Whittington (2014) have combined robust decision-making principles with a 'real-options' approach to capital investment (e.g. options to defer, expand, contract, abandon, switch use, or otherwise alter a capital investment) to explore investment strategies under climate change uncertainty for new multi-purpose dams on the Blue Nile. It was found that there was no single investment plan that performed best across a range of plausible future runoff conditions.

One response to this investment dilemma is, in the first instance, to avoid large supply-side capital investments which can lead to resource depletion, and to seek out incremental investments based on water use efficiency that are essentially 'no regret' i.e. they should be made in any case from a sustainability perspective. Investments in water saving technologies and demand management measures can form the cornerstone of this approach.

A disproportionate focus on GHG-induced climate change can lead to policy-making that is too narrowly focussed. Rodolfo and Siringan (2006) have reported that policy-makers in a number of government sectors in the Philippines were focussing on predicted sea-level rise of one to three millimetres per year due to global warming as a cause of worsening floods around Manila Bay, but were oblivious to, or ignoring, the principal reason: excessive groundwater extraction that was lowering the land surface by several centimetres to more than a decimetre per year. Such a misplaced focus allowed the government to treat flooding as a lesser problem that could be mitigated through large infrastructural projects that would be both ineffective and vulnerable to corruption. Funds would be better spent on preventing the subsidence by reducing groundwater pumping by fishpond operators (Rodolfo and Siringan 2006). Similarly, water scarcity may be attributable to a number of non-climatic factors, including uncontrolled demand/over-extraction from surface and groundwater resources, poor governance, and uneconomical uses. The full decision space needs to be explored in identifying 
responses that are robust and resilient to future climatic and socio-economic uncertainties, and sustainable in economic, social and environmental terms.

Rather than rely solely on climate model-driven impact assessments, Pielke et al. (2009) suggest the use of integrated assessments within the framework of vulnerability as a complementary approach, with an emphasis on risk assessment and disaster prevention (Kabat et al. 2004). Pielke et al. (2012) expand upon the use of this bottom-up, resource-based vulnerability approach to assessing the major threats to local and regional resources from extreme events, including those from climate but also from other social and environmental issues. They argue that this is a more inclusive way of assessing risks, including from climate variability and climate change, than using the outcome vulnerability approach adopted by the Intergovernmental Panel on Climate Change (IPCC).

Brown and Wilby (2012) assess climate risks using a form of sensitivity analysis ('stresstesting') to determine what climate characteristics a water supply system serving a metropolitan area in Massachusetts might be most sensitive to/at risk from. First, they demonstrated that GCM projections underestimated the variability statistics (standard deviation and lag-one autocorrelation) of streamflow for a region of the northeast United States based on a widely used, bias-corrected and statistically downscaled source of GCM projections (Maurer et al. 2007). Secondly, they used resampling of the historical record of annual Net Basin Supply (inflows net evaporation) to demonstrate the sensitivity of the system reliability to the variability in mean and standard deviation, and to assess which combinations of these statistics are most critical for reliability. They suggest that GCM projections can be mapped into the same reliability space to see what clustering they generate.

There is a close resemblance to the stochastic modelling approach to system 'stress-testing' outlined by Brown and Wilby (2012) and the 'synthetic hydrology' approach pioneered by Harold A Thomas and his colleagues in the 1950s as part of the Harvard Water Programme (Maass et al. 1962). Then, the rationale was that short historic records did not sample adequately the range of events (droughts etc.) that might be expected in the future, and that Monte Carlo sampling of synthetic streamflows generated by a stochastic model fitted to the historic record offered a basis for assessing future risks which were essentially associated with climatic variability. The aim was to reproduce, in synthetic streamflow series, the statistical characteristics to which a water resource system was sensitive, including interannual variability. Over subsequent decades, the modelling of long-term persistence in climatic and streamflow records became a focus for stochastic modelling (O'Connell et al. 2016) and, as noted above, it would seem judicious to take advantage of this modelling legacy in climate risk assessment. In cases where GCMs cannot reproduce the observed LTP in control period simulations (Johnson et al. 2011), it would seem prudent to enhance the level of LTP in stochastic model simulations for stress testing and vulnerability assessments, since the climate is expected to become more variable under global warming.

Under the auspices of the Alliance for Global Water Adaptation (AGWA), García et al. (2014) have conducted a very useful stock-take of the current understanding of climate, of mainstreaming adaptation into water resources management, of key tools supporting climate risk assessment, and the identification of robust and resilient adaptation strategies. They then advocate moving beyond the top-down downscaling approach towards a bottom-up approach to adaptation which is based on merging resilience and robustness from both engineering and ecological perspectives, and set out a decision support framework for doing this. This framework should embed a process of creating explicitly-flexible decision pathways so that the risk of making decisions on indivisible and irreversible investments is minimized. Critical 
here is the development of economic analytical methodologies that (a) estimate the costs of maintaining multiple options and flexibility, (b) evaluate the trade-offs between waiting for more certain information before implementation versus acting in the short term with less information, and (c) design multiple decision-making pathways. This approach needs to be supported by flexible governance mechanisms.

\section{Managing the Supply-Demand Imbalance: Economic and Technological Aspects}

\subsection{An Integrated Economic Approach}

The growing world water crisis and supply-demand imbalance have been discussed in the Introduction. While the series of World Water Assessment Reports (WWAP, 2003; 2006; 2009; $2012 ; 2014 ; 2015 ; 2016$ ) have served to document the scale of the problem through various indicators and well documented case studies from around the world, a clear strategy for how to tackle the problem has proved elusive. As noted, substantial progress has been made with implementing the IWRM approach, and while it can potentially deliver a more sustainable approach to water resources management, it is not apparent how the water sector can overcome its burgeoning crisis. In particular, large investments are needed in water saving technologies to help close the demand-supply gap over the coming decades, yet the overriding preoccupation is still with supply-side solutions, exacerbated by the perceived climate change threat to the reliability of supplies, the large uncertainty in the predictions from climate models, and the dominance which this occupies in government sector thinking. Whatever happens to the climate, population and socio-economic growth will continue to exacerbate the supplydemand imbalance, and a greater focus is needed on the development of economic analyses that can demonstrate the investments that are needed, and how they might be mobilized to address the demand-supply gap.

There is evidence that the leading G20 and other countries are concerned about the potential impacts of water scarcity on their economies. In 2015, the World Economic Forum's Global Risks Report (World Economic Forum 2015) identified Water Crises as the global risk of highest concern for the next 10 years. Moreover, major multi-national organizations are becoming increasingly concerned about the threat that increasing water scarcity poses to their businesses, as evidenced by the formation of the 2030 Water Resources Group in 2008 to contribute new insights to the critical issue of water scarcity, and to mobilize action. Members include McKinsey \& Company, the International Finance Corporation (IFC) of the World Bank Group, and a consortium of business partners: The Barilla Group, The Coca Cola Company, Nestlé SA, New Holland Agriculture, SABMiller plc, Standard Chartered and Syngenta AG. They released a remarkably well focused report in 2009 which demonstrated how growing water scarcity can be mitigated affordably and sustainably. By providing greater clarity on the scale of the water challenge and the cost of the solutions, it offers a fact-based tool to help stakeholders make informed investment decisions and guide policy discussions.

The departure point for the 2030 Water Resources Group Report (the Report in what follows) is the observation that the growing global imbalance between demand and supply (the 'water gap') should be mobilizing new investments to deliver water use efficiencies, and augment supplies where needed. However, while calls for action increase, the evidence suggests that the situation is getting worse. By 2030, it is estimated that, under an average 
economic growth scenario, and if no efficiency gains are assumed, global annual water requirements would grow from 4500 (in 2009) to 6900 billion $\mathrm{m} 3$. This is a full $40 \%$ above current accessible, reliable supply (defined in the Report as that which can be supplied with $90 \%$ reliability). Moreover, this global figure represents the aggregation of a very large number of local gaps, some of which reveal an even worse situation: the Report estimates that one-third of the population, concentrated in developing countries, will live in basins where this deficit is larger than $50 \%$.

Progress in closing the water gap is not encouraging. The annual rate of efficiency improvement in agricultural water use between 1990 and 2004 was approximately 1\% across both rain-fed and irrigated areas, with a similar rate of improvement in industry. If this rate of progress was sustained to 2030, the Report estimates that improvements in water efficiency would address only $20 \%$ of the water gap, leaving a large deficit to be filled. Similarly, business-as-usual investment in infrastructure would cover only a further $20 \%$ of the gap. Based on this historical rate of progress, the Report does not consider that the water sector, if left to its own devices, can close the gap. Even at the present time, gaps between water demand and supply exist and are being closed through aquifer depletion or by not meeting environmental water requirements, or when supply is considered from the perspective of reliable rather than average availability. Recent evidence suggests that the depletion of aquifers worldwide is increasing at an alarming rate, driven mainly by withdrawals for irrigation; 11 $\%$ of this depletion is embedded in international food trade (Dalin et al. 2017).

To demonstrate how the water gap can be closed, the Report employs an economic analysis of the different water use efficiency and supply-side options for closing the gap in 2030. The key tool in this approach is a 'water marginal cost curve' which presents the results of a microeconomic analysis of the unit cost and incremental availability potential of a wide range of existing technical measures (Fig. 1). The measures are ordered in terms of their unit costs, and the results are presented in blocks, with the width denoting incremental availability, and the height, unit cost.

Using the cost curve approach, an analysis was conducted in four countries with drastically different water issues: China, India, South Africa and Brazil (Sao Paulo state), which will

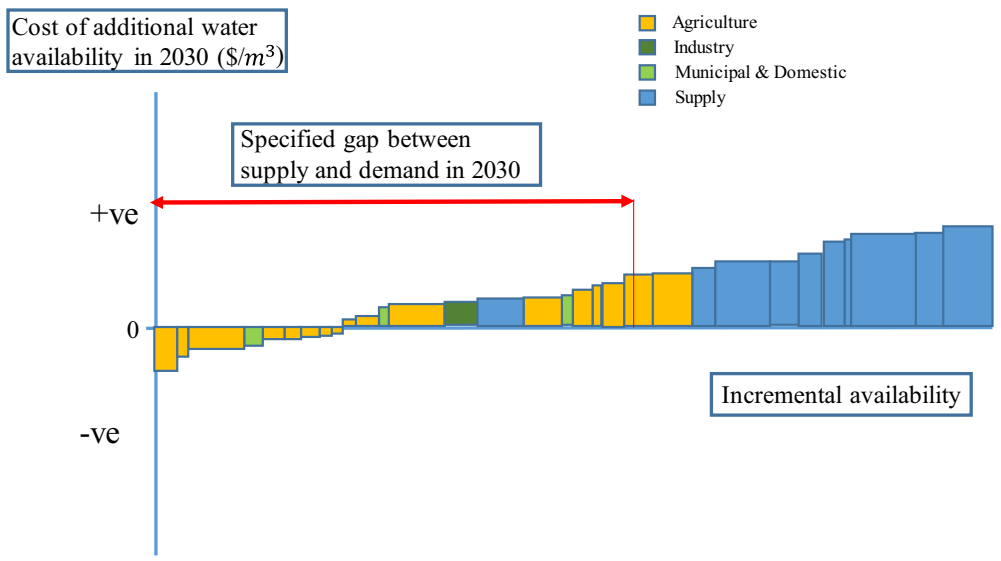

Fig. 1 Schematic of Water Availability Cost Curve (redrawn after 2030 Water Resources Group 2009). The width of the block represents the amount of additional water that becomes available from adoption of the measure. The height of the block represents its unit cost. Negative costs indicate savings. The colour codes represent water availability from the different demand-side and supply-side measures 
collectively account for $40 \%$ of the world's population, $30 \%$ of global GDP and $42 \%$ of projected water demand in 2030. The Report shows that, if a balanced portfolio of demandand supply-side measures is adopted in each country, the projected water requirements in 2030 can be met at an estimated cost of $\$ 19$ billion per year for these countries, or just under $0.06 \%$ of their combined forecast GDP for 2030. If the results are scaled up to the global level, the cost is estimated at \$50-60 billion. On the other hand, if only traditional supply-side measures are implemented, an additional capital expenditure of up to $\$ 200$ billion per year globally would be required to close the water gap. This is four times more than the balanced approach and more than double what is currently spent on water resource provision. The Report notes that the projected 2030 global water gap emerges from aggregation across basins, countries and regions where there are multiple developing water crises, and both the challenges and the solutions will differ widely with geography and socio-economic setting.

Since the publication of its Report in 2009, the 2030 Water Resources Group has formed an alliance with the World Economic Forum, and, with financial support from the IFC, bilateral aid agencies and private sector companies, is creating an operational programme. Its value proposition is that it can leverage a unique public-private-expert-civil society network to help government water officials and water professionals bring new actors, for example private sector, multi- and bi-lateral development agencies, and domestic and international development finance institutions, into the national water sector arena. By 2016, its plan was to engage with up to 15 countries, including lower income countries.

\subsection{Technological Aspects}

As water resource systems become more stressed, it is important that they are operated so that water use efficiency is maximized. Moreover, the need to reduce greenhouse gas emissions requires that energy use associated with pumping operations etc. is reduced. To achieve this, wider use will need to be made of real time monitoring, forecasting and control so that a much tighter level of operational control over the distribution and use of water is achieved, and water losses minimized. This can form part of a robust water resources management adaptation strategy, since it should be performed in any case on the grounds of the sustainable and economically efficient use of water.

Agriculture is the biggest water user, with irrigation accounting for $70 \%$ of global water withdrawals (UN Water 2013). Despite the known benefits of drip irrigation in terms of reduced water use and increased crop productivity, the percentage of irrigated land that is equipped with drip irrigation remains very small. A major barrier to uptake by farmers is cost, particularly in the developing world. Techological advances are needed similar to that reported on recently at MIT which demonstrated that the cost of solar-powered drip systems could be cut by half by optimizing the drippers (Shamshery et al. 2017).

Global modelling of irrigation efficiency has shown that replacing surface systems by sprinkler or drip systems could, on average across the world's river basins, reduce the nonbeneficial consumption at river basin level by 54 and $76 \%$, respectively, while maintaining the current level of crop yields (Jägermeyr et al. 2015). Accordingly, crop water productivity would increase by 9 and 15\%, respectively, and by much more in specific regions such as in the Indus basin.

Losses from irrigation canals and their inefficient operation contribute to the nonproductive use of irrigation water. Malaterre (2007) reported that, despite recent new construction or modernization of existing canals, the percentage of automated irrigation canals in 
the world is still below 5\%. Plusquellec (2002) suggested that no further complacency was acceptable in addressing the poor management practices in large irrigation systems. The failure to understand the links between the technical improvements to large surface irrigation schemes needed and the required reforms may exacerbate the problem of water scarcity and threaten food security in the future. Plusquellec considered that the magnitude of investments and capacity building in human resources to achieve this goal was likely to be underestimated.

As migration to urban centres across the globe increases, and as lifestyles change in the emerging economies, the need to address water use inefficiency in the urban sector is also urgent. The World Bank estimates that on average, city water utilities lose up to $30 \%$ of their water resources through leaks or unaccounted for water. Poor management of pressure is a major factor in leakage loss, and the real-time control and optimization of pressure in networks (Jamieson et al. 2007) is again an area of unfilled potential, even in cities in the developed world. Moreover, there is also a need to understand how water is used domestically through identifying its microcomponents (e.g., showers, toilets, washing machines etc) and to make residents more aware of how they might reduce their use through intelligent 'smart meters' (Nguyen et al. 2013). Marlow et al. (2013) discuss the broader critical issues characterizing emerging approaches to urban water management and infrastructure provision under socioeconomic and environmental pressures.

Basin, regional and national water resource systems could be operated much more efficiently through the implementation of operational real-time control. While optimal real-time control at basin scale is not feasible, near optimal control can be achieved through a hierarchical control system whereby the system is broken down into sub-systems that are controlled individually through targets or 'set-points' that are based on medium/long-term operating policies established by the regional/basin centre (Fig. 2). This approach, which was first proposed back in the 1970s (Jamieson 1976; O'Connell 1980), would help achieve basin scale efficiency, and with emerging water scarcity, could also provide greater transparency to competing users on how water is being allocated and used.

Institutional, governance and cultural barriers have to be overcome with the implementation of new technologies. In the context of managing vulnerability to drought and climatic variability and enhancing livelihood resilience in sub-Saharan Africa, Shiferaw et al. (2014)
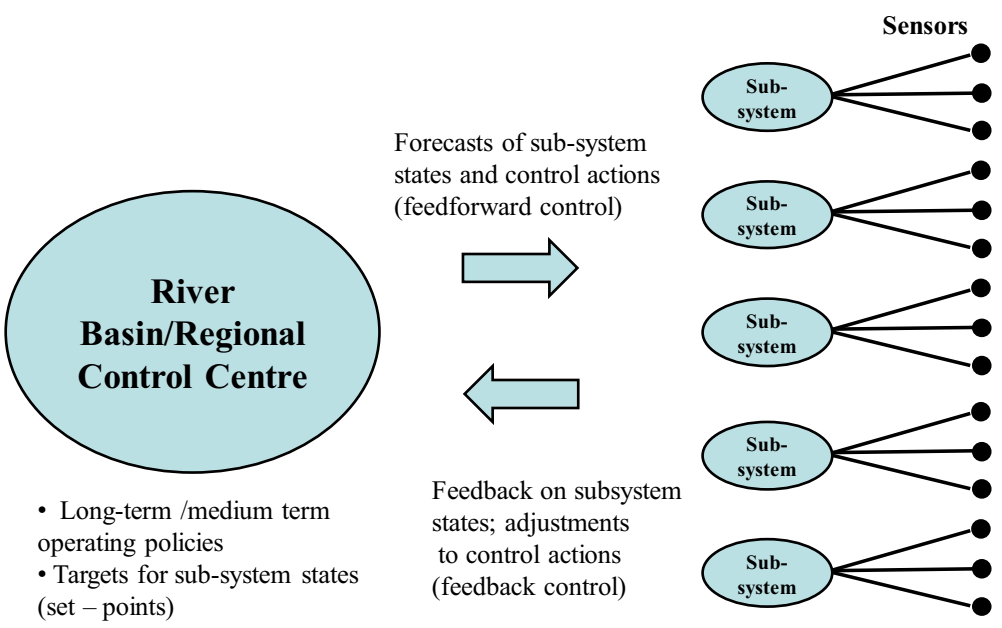

Fig. 2 Schematic of a river basin/regional real-time operational control system 
advocate a proactive approach that combines promising technological, institutional and policy solutions to managing the risks within vulnerable communities implemented by institutions operating at different levels (community, sub-national, and national) as a way forward.

\section{Modelling the Human Dimension of Adaptation}

Embedded within all approaches to the modelling of adaptation, whether at the level of cities, basins or countries, are multiple assumptions about how humans will use water in the future, and how they will adapt to developing water scarcity. Annual demand projections typically combine average per capita water use with population projections in estimating domestic water use demand, but in reality, there is wide variation in the per capita use. Irrigation water use involves decisions by individual farmers on when to irrigate, and how much water to apply. As discussed in section 4.1, water saving technologies and efficient human use will be critical to closing the water gap, as will the uptake of such technologies by individual humans and organizations. Human choices and decisions therefore have a critical bearing on the success or otherwise of adaptations. What are the right levers that need to be activated to induce individual users, communities and organizations to be more efficient in their water use operations, and how can we model the responses to these levers? Unfortunately, the price of water is still way below the level of at which it will induce careful and efficient use, and water wastage is still widespread. The bottom-up approach to climate adaptation reflects a focus on the factors and conditions that enable successful coping with climate and socio-economic change at the level of individuals, households and communities, which emphasizes the human dimension of adaptation.

A schematic of a water resource system is presented in Fig. 3 which shows that a Human System interacts with a Hydrologic System through Infrastructure and Technologies which redistribute water in time and space to meet human demands. Due to the difficulty of representing the complexity of human activities and choices in using water, incorporating the human dimension into the modelling of adaptation in water resource systems has proved challenging. A recent review of 'Human-Hydrology Systems Modelling' (O'Donnell and O'Connell 2017) has shown that there is wide diversity in the approaches taken to modelling the interactions between human activities and hydrologic systems, and that the subject is still in

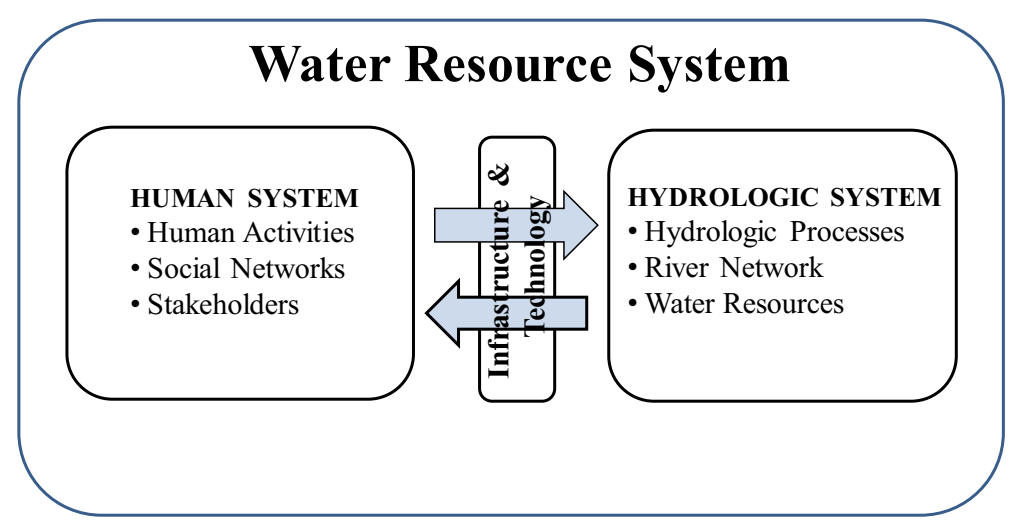

Fig. 3 A water resource system as a complex coupled human and hydrologic system 
an evolutionary state. However, the Coupled Human and Natural System (CHANS) paradigm seems to be emerging as a basis for modelling the interactions and feedbacks that characterize human-hydrologic systems, as it has a relatively well established track record in ecology and ecosystems modelling (e.g. Alberti et al. 2011; An 2012; Liu et al. 2007; Monticino et al. 2007), and there is increasing synergy between ecosystem and water resources research in the context of environmental water needs. O'Connell and O'Donnell (2014) suggest that the CHANS approach could form the basis of a new era of systems modelling in the hydrology and water resources fields that is needed to meet the challenge of managing the now complex catchment systems of the Anthropocene. Cai (2014) also suggests that the next generation of river basin models should be based on a CHANS modelling approach. The CHANS approach has a strong emphasis on real world issues, often engaging in stakeholder engagement and participatory research, but the approach also addresses the need for fundamental understanding (An 2012; Liu et al. 2007).

To provide a general framework for adaptation modelling, O'Donnell and O'Connell (2017) have embedded a Coupled Human and Hydrologic System (CHAHS) model within a DriverPressure-State-Impact-Response (DPSIR) framework (e.g. Bürgi et al. 2004; Verburg 2006) (Fig. 4), The term 'Natural System' in CHANS has been replaced by 'Hydrologic System', as rural and urban catchments and groundwater systems are no longer natural but have been heavily impacted by human activity. The overall goal of the proposed framework is to gain insight into how these coupled human and hydrologic systems might co-evolve under alternative climatic, socio-economic and regulatory futures that are uncertain (the Drivers). In a water resources context, the interactions between the two systems arise as a consequence of the occurrence of water scarcity associated with droughts and/or a developing supply-demand

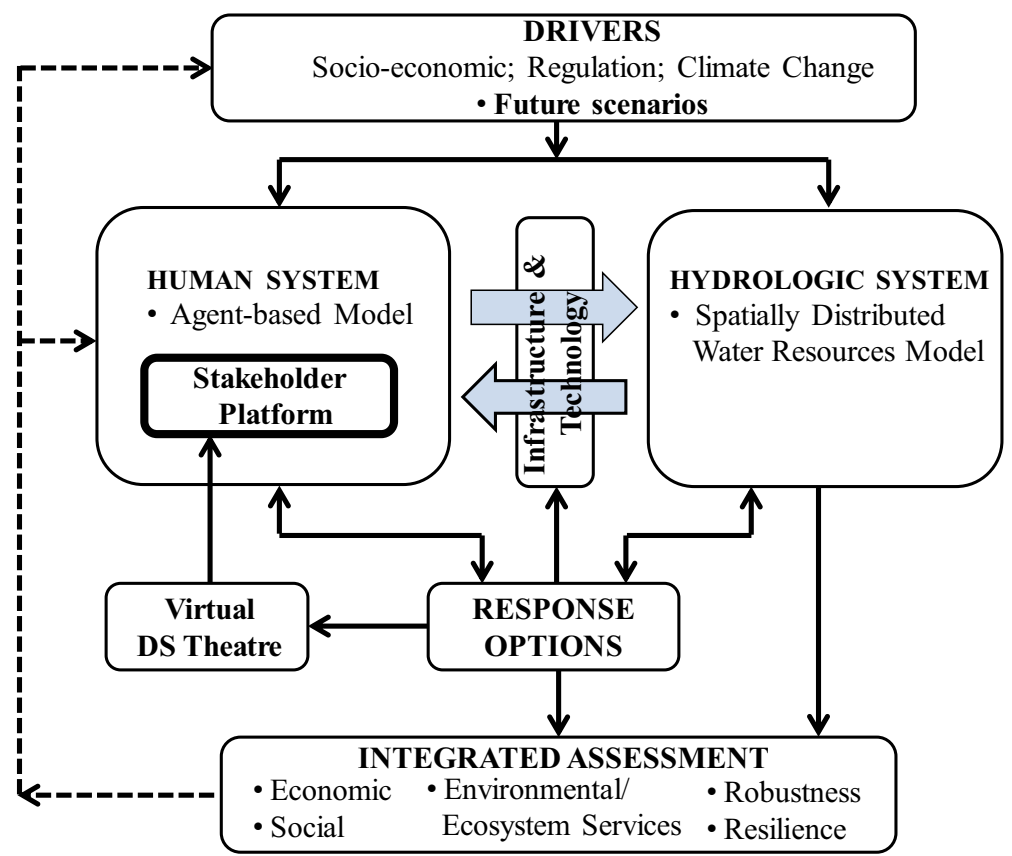

Fig. 4 Coupled Human and Hydrologic System (CHAHS) modelling and adaptation framework (modified after O'Donnell and O'Connell 2017) 
imbalance, and the human responses to the latter. The Responses should be sustainable in economic, social and environmental terms, and robust and resilient under uncertain futures. They include 'hard' Infrastructure and Technology interventions (e.g. supply-side infrastructure, water saving technologies) that can mitigate water scarcity impacts, and 'soft', interventions such as institutional reform, building resilience, human water saving measures etc. Agent-based modelling can be used to represent the social processes whereby humans react when impacted by water scarcity, and also the adaptation decision-making processes at agency/governmental level. Agents therefore represent the different stakeholders in the decision-making process, and the Stakeholder Platform (Fig. 4) is a key component in the representation of the human system and in decision-making. As a consequence, stakeholders can appreciate how their preferences and views can affect other stakeholders economically and socially, leading to compromise. They are supported by a Virtual Decision Support Theatre which can depict virtual rural (e.g. Donaldson-Selby et al. 2012) and urban futures (e.g. Edsall and Larson 2009) and possible interventions/responses. Responses emerge from the Stakeholder Platform with support from technical experts, as represented by the twoway interaction in Fig. 4. These are then evaluated though an Integrated Assessment (IA) process (eg Rotmans and Van Asselt 1996), the outcomes of which are fed back to the Human System and specifically the Stakeholder Platform, with iteration eventually leading to the preferred Responses to be implemented that satisfy the IA criteria. There is a parallel two-way interaction between the Responses and the water resource system model; water resource system infrastructure would be represented within the model, and the impacts fed through to the IA process, and back to the Stakeholder Platform through the feedback loop.

Human and Hydrologic systems interact continuously over time as a consequence of drought events and developing water scarcity, and the Responses that are implemented. The time scales could range from that associated with an individual hydrological event e.g. a drought, to long-term decadal CHAHS simulations that evaluate the consequences of proactive and reactive investment strategies under uncertain climatic and socio-economic futures (O’Connell and O'Donnell, 2014).

A specific challenge in the development of an agent-based model (ABM) is choosing an appropriate methodology to represent human behaviour. In general, this is beyond the capability of ABM, but specific modes of behaviour can be modelled. Utility maximisation may provide a useful starting point, but is rarely plausible as the agents' real world counterparts do not generally conform to such optimization. An alternative strategy is 'satisficing' in which an agent continues to seek a solution until it finds one that is adequate, based on an aspirational target (Schlüter and Pahl-Wostl 2007). In the context of exploring the role of important factors determining the degree of trust and cooperation in a group, Pahl-Wostl and Ebenhöh (2004) have assumed that agents can be characterised by a set of attributes, and their behaviour described by a set of simple decision heuristics.

It is recognised that ABM is not mature, and has limitations. The majority of applications involve the exploration of hypotheses, particularly involving futures about which there is deep uncertainty, and the investigation of emergent behaviour that might not have been anticipated a priori. Relatively few applications attempt system prediction. ABM does not yet have a standardised set of procedures for model development and agent representation, and hence models and results are difficult to replicate (Grimm et al. 2010; Macal and North 2010). Moreover, model validation is largely judgemental, based on expert opinion, qualitative comparison and sensitivity analysis (Heath et al. 2009). More rigorous validation approaches 
are needed based on comparison against an independent set of data, such as real-world observations, or outcomes from another model or theory (Zellner 2008).

Despite the challenges set out above, it is expected that the use of agent-based modelling (ABM) will continue to expand in the water resource management field, and specifically in bottom-up adaptation studies. O'Donnell and O'Connell (2017) review a wide range of applications under the headings of Land Use and Agriculture, Groundwater, Irrigation, Flooding and Water Resources Management. Examples are Bithell and Brasington (2009: water distribution to farmers); Galán, et al. (2009: domestic water supply management); Holtz and Pahl-Wostl (2012: groundwater depletion) and O'Connell and O'Donnell (2014: flood risk management).

It is recognised that water related problems are often value-laden and subjective, requiring a greater role for stakeholder participation (Ascough et al. 2008). Here, ABM can promote social learning among stakeholders (Pahl-Wostl 2002; Pahl-Wostl and Hare 2004; Pahl-Wostl 2006) and make them more aware of fairness and equity in sharing water resources (Nancarrow and Syme 2004). Valkering et al. (2004) developed an agent based model representing a negotiation among stakeholders concerning river management.

\section{Conclusions}

The foregoing review has demonstrated that the current balance of water resources research is too skewed towards climate change impact assessment and adaptation at the expense of focussing on the many challenges associated with closing the water gaps that will emerge for many countries in the coming decades, irrespective of what happens to the climate. An appraisal of the evidence for anthropogenic signals in precipitation and streamflow records shows that such signals are difficult to detect in the presence of natural climatic variability. As water resources systems become more stressed, it appears that natural interannual climatic variability will be the major determinant of water supply reliability in the coming decades, and that climate risk assessments should ensure that this is reproduced in stochastic representations of future climate. In this context, there has been an appropriate shift away from top-down climate model-driven impact assessments to bottom up risk assessments that focus on (a) simulating those characteristics of climate variables to which water resource reliability is sensitive, and (b) assessing the vulnerabilities of humans, communities and cities to socioeconomic and climatic stresses on water supplies. In this context, there has been a misplaced emphasis on invoking the hypothesis of nonstationarity in the belief that the climate is changing due to GHG emissions even though clear, widespread evidence to support this has yet to emerge. Moreover, from the IPCC evidence reviewed in section 2, it is expected that natural climatic variability will predominate over the time scale that adaptation will be needed to close the water gap. Therefore, climate risk assessments should be based on modelling natural climatic variability in the first instance. For stress-testing purposes, this variability can be enhanced to reflect reliable information from GCMs when this is available.

For too long, water has been left out of central government economic planning, and the water sector is expected to deliver whatever services are needed to support economic growth while being starved of the necessary investments. As a consequence, the water gap will continue to grow for BRIC, MINT and other countries with growing populations and economies unless water is brought into the mainstream of national economic planning. The 2030 Water Resources Group Report (Water Resources Group 2009) has demonstrated that an incremental balanced approach to closing the water gap globally in 2030 prioritizes 
investments in water saving technologies over supply-side solutions; the balanced approach is estimated to cost $\$ 50$ billion per annum while a supply-side approach would cost four times this amount, or twice what is currently invested in supply-side solutions annually. There is therefore a heavy cost premium associated with the latter approach which will also lead to degradation of the water environment. The balanced approach is affordable, offers a pathway to sustainability, and prioritizes investments that are incremental and should be made anyway, irrespective of future climatic and socio-economic uncertainties. The 2030 Water Resources Group Report acknowledges that the data used for its analyses had deficiencies, but these cannot negate the main outcome. It is also recognised that new stakeholder dialogues will be needed to mobilize the necessary investments and to promote a more dynamic approach in the water sector, and these are already being pursued (2030 Water Resources Group 2012). Through its potentially transformative public-private sector partnership and its capacity to mobilize debates and decision-making at the highest levels, the 2030 Water Resources Group has the potential to mobilize the investment that is needed to transform the water sector and make a significant impact on closing the water gap for some countries. Moreover, it has brought an integrated economic approach back into the mainstream of water resources planning and management, and focussed on adaptation to the population growth and socioeconomic change that will happen in the coming decades, irrespective of what happens to the climate. Otherwise, economic growth itself, lifestyles and livelihoods will be placed at risk.

That human-induced climate change may make water crises worse in the long run is not in question, but these water crises will emerge in any case and within a shorter time scale than that within which global warming is expected to impact significantly upon the hydrological cycle. As water resource systems become increasingly stressed, adaptation to the socioeconomic drivers of change is therefore the main priority, with a major emphasis on demand-side interventions and sustainability.

In the 1950/60s, the Harvard Water Programme demonstrated how stochastic modelling/synthetic hydrology, economics and systems analysis could be integrated to deliver a transformative interdisciplinary approach to water resources planning (Maass et al. 1962). This programme should be revisited, not to reinvent it as some have suggested based on the hypothesis of nonstationarity (Milly et al. 2008), but to ensure that its legacy is not lost.

In recognition of the current need to incorporate the human dimension more explicitly into adaptation modelling frameworks, a Coupled Human and Hydrologic System modelling framework has been proposed in which the Human System can be represented using Agentbased Modelling (ABM). Adaptation fundamentally depends on gaining agreement from stakeholders on what is fair and equitable in sharing scarce water resources, in getting farmers to embrace more efficient irrigation practices and technologies, and in getting domestic water users to reduce their consumptions. While representing the full complexity of human behaviour is beyond what ABM can achieve, it can still enhance our understanding of the complex interactions between human and hydrologic systems in adapting to water scarcity, and in looking for emerging behaviour under such conditions that might not have been anticipated a priori. CHAHS modelling of adaptation measures could be used to inform the 2030 Water Resources Group cost curve approach to closing the water gap, particularly on the human barriers to the implementation of water saving technologies, and how they might be overcome.

Acknowledgements The author acknowledges helpful comments on a draft of this paper by Greg O'Donnell and Ezio Todini. 
Open Access This article is distributed under the terms of the Creative Commons Attribution 4.0 International License (http://creativecommons.org/licenses/by/4.0/), which permits unrestricted use, distribution, and reproduction in any medium, provided you give appropriate credit to the original author(s) and the source, provide a link to the Creative Commons license, and indicate if changes were made.

\section{References}

Alberti M et al (2011) Research on coupled human and natural systems (CHANS): approach, challenges, and strategies. Bull Ecol Soc Am 92(2):218-228. doi:10.1890/0012-9623-92.2.218

An L (2012) Modeling human decisions in coupled human and natural systems: review of agent-based models. Ecol Model 229:25-36

Ascough JC, Maier HR, Ravalico JK, Strudley MW (2008) Future research challenges for incorporation of uncertainty in environmental and ecological decision-making. Ecol Model 219(3-4):383-399

Bateman J (2014) China's looming water crisis. The Ecologist. http://www.theecologist.org/News/news analysis/2291208/chinas_looming_water_crisis.html

Bithell M, Brasington J (2009) Coupling agent-based models of subsistence farming with individual-based forest models and dynamic models of water distribution. Environ Model Softw 24(2):173-190. doi:10.1016/j. envsoft.2008.06.016

Brown C, Wilby RL (2012) An alternate approach to assessing climate risks. Eos Trans AGU 93(41):401

Bürgi M, Hersperger A, Schneeberger N (2004) Driving forces of landscape change - current and new directions. Landsc Ecol 19(8):857-868. doi:10.1007/s10980-004-0245-8

Cai X (2014) Modeling river basins as coupled human and natural systems, NCSA, University of Illinois at Urbana-Champaign

Clarke RT (2010) On the (mis)use of statistical methods in hydro-climatological research. Hydrol Sci J 55(2):139-144

Cohn TA, Lins HF (2005) Nature's style: naturally trendy. Geophys Res Lett 32:L23402. doi:10.1029/2005 GL024476

Dalin C, Wada Y, Kastner T, Puma MJ (2017) Groundwater depletion embedded in international food trade. Nature 543:700-704. doi:10.1038/nature21403

Donaldson-Selby G et al (2012) Testing public preferences for future land uses and landscapes. In: Singleton A (ed) proceedings of the GIS research UK 20th annual conference, University of Lancaster, pp 139-144

Dong $\mathrm{H}$ et al (2013) Regional water footprint evaluation in China: a case of Liaoning. Sci Total Environ 442: 215-224. doi:10.1016/j.scitotenv.2012.10.049

Edsall RM, Larson KL (2009) Effectiveness of a semi-immersive virtual environment in understanding humanenvironment interactions. Cartogr Geogr Inf Sci 36(4):367-384. doi:10.1559/152304009789786317

Galán JM, López-Paredes A, del Olmo R (2009) An agent-based model for domestic water management in Valladolid metropolitan area. Water Resour Res 45(5):W05401. doi:10.1029/2007WR006536

García LE, Matthews JH, Rodriguez DJ, Wijnen M, DiFrancesco KN, Ray P (2014) Beyond downscaling: a bottom-up approach to climate adaptation for water resources management. AGWA report 01. World Bank Group, Washington, DC

Gleick PH (2000) The changing water paradigm. A look at twenty-first century water resources development. IWRA Water Int 25(1):127-138

Grimm V et al (2010) The ODD protocol: a review and first update. Ecol Model 221(23):2760-2768. doi:10.1016/j.ecolmodel.2010.08.019

Hartmann DL et al (2013) Observations: Atmosphere and Surface. Chapter 2.6 on Changes in Extremes, 215. In: Stocker et al (eds) Climate Change 2013: The physical science basis. Contribution of Working Group I to the Fifth Assessment Report of the Intergovernmental Panel on Climate Change. Cambridge University Press, Cambridge

Hasselmann K, Cubasch U, Mitchell JFB, Roeckner E, Voss R, Waszkewitz J (1997) Multi-fingerprint detection and attribution of greenhouse-gas and aerosol-forced climate change. Climate Dyn 13:613-634

Heath B, Hill R, Ciarallo F (2009) A survey of agent-based modeling practices (January 1998 to July 2008). J Artif Soc Soc Simul 12(4):9

Hoekstra AY (2011) The global dimension of water governance: why the river basin approach is no longer sufficient and why cooperative action at global level is needed. Water 3(1):21-46. doi:10.3390/w3010021

Holtz G, Pahl-Wostl C (2012) An agent-based model of groundwater over-exploitation in the upper Guadiana, Spain. Reg Environ Chang 12(1):95-121. doi:10.1007/s10113-011-0238-5

Hurst HE (1951) Long term storage capacity of reservoirs. Trans Am Soc Civ Eng 116:770-799

Hurst HE (1956) Methods of using long-term storage in reservoirs. Proc Inst Civ Eng 5:519-543

IPCC (2012) Managing the risks of extreme events and disasters to advance climate change adaptation. In: Field $\mathrm{CB}$ et al (eds) A special report of working groups I and II of the Intergovernmental Panel on climate change. Cambridge University Press, Cambridge 
Jägermeyr J, Gerten D, Heinke J, Schaphoff S, Kummu M, Lucht W (2015) Water savings potentials of irrigation systems: global simulation of processes and linkages. Hydrol Earth Syst Sci 19:3073-3091. doi:10.5194 /hess-19-3073-2015

Jamieson DG (1976) Suggestions for future policy on operational river basin management in Thames Water. Internal Report, Thames Water Authority, p 17

Jamieson DG, Shamir U, Martinez F, Franchini M (2007) Conceptual design of a generic, real-time, near-optimal control system for water-distribution networks. J Hydroinf 9(1):3-14

Jeuland M, Whittington D (2014) Water resources planning under climate change: assessing the robustness of real options for the Blue Nile. Water Resour Res 50:2086-2107. doi:10.1002/2013WR013705

Jia Y, Ding X, Wang H, Zhou Z, Qiu Y, Niu C (2012) Attribution of water resources evolution in the highly water-stressed Hai River Basin of China Water Resour Res 48. doi:10.1029/2010WR009275

Johnson F, Westra S, Sharma A, Pitman AJ (2011) An assessment of GCM skill in simulating persistence across multiple time scales. J Clim 24:3609-3623

Kabat P et al (eds) (2004) Vegetation, water, humans and the climate: a new perspective on an interactive system. Springer, Berlin, p 566

Koutsoyiannis D (2003) Climate change, the Hurst phenomenon, and hydrological statistics. Hydrol Sci J 48:324. doi:10.1623/hysj.48.1.3.43481

Koutsoyiannis D (2010) Hurst-Kolmogorov processes and uncertainty. Proc. Workshop on nonstationarity, hydrologic frequency analysis, and water management. Colorado Water Institute Information Series No. 109, Boulder, pp 66-80

Koutsoyiannis D, Montanari A (2015) Negligent killing of scientific concepts: the stationarity case. Hydrol Sci J 60:1174-1183. doi:10.1080/02626667.2014.959959

Liu J et al (2007) Coupled human and natural systems. AMBIO: J Hum Environ 36(8):639-649

Liu Y, Zhang J, Wang G, Liu J, He R, Wang H, Liu C, Jin J (2012) Assessing the effect of climate natural variability in water resources evaluation impacted by climate change. Hydrol Process. doi:10.1002/hyp.9251

Lu F, Ocampo-Raeder C, Crow B (2014) Equitable water governance: future directions in the understanding and analysis of water inequities in the global south. Water Int 39(2):129-142

Maass A et al (1962) Design of water-resource systems. Cambridge, Harvard University Press, p 660

Macal CM, North MJ (2010) Tutorial on agent-based modelling and simulation. J of Sim 4(3):151-162

Malaterre P-O (2007) Control of irrigation canals: why and how? In: Garcia Navarro P, Playan E (eds) Proc. international workshop on numerical modelling of hydrodynamics for water resources. University of Zaragoza, Taylor and Francis (Balkema Ed.), pp 271-292

Markonis Y, Koutsoyiannis D (2014) Climatic variability over time scales spanning nine orders of magnitude: connecting Milankovitch cycles with Hurst-Kolmogorov dynamics. Surv Geophys 34(2). doi:10.1007 /s10712-012-9208-9

Marlow DR, Moglia M, Cook S, Beale DJ (2013) Towards sustainable urban water management: a critical reassessment. Water Res 47(20):7150-7161. doi:10.1016/j.watres.2013.07.046

Matalas NC (1997) Stochastic hydrology in the context of climate change. Climate Change 37(1):89-101

Matalas NC (1998) Note on the assumption of hydrological stationarity. In: Schilling K, Stakhiv E (eds) Global change and water resources management, water resources update no 112. University Council on Water Resources, Carbondale, pp 64-72

Maurer EP, Brekke L, Pruitt T, Duffy PB (2007) Fine-resolution climate projections enhance regional climate change impact studies. Eos Trans AGU 88(47):504. doi:10.1029/2007EO470006

Milly PCD, Betancourt J, Falkenmark M, Hirsch RM, Kundzewicz ZW, Lettenmaier DP, Stouffer RJ (2008) Stationarity is dead: whither water management. Science 319:573-574

Monticino M, Acevedo M, Callicott B, Cogdill T, Lindquist C (2007) Coupled human and natural systems: a multi-agent-based approach. Environ Model Softw 22(5):656-663

Nancarrow BE, Syme GJ (2004) Fairness principles in allocating water: integrating views of different agents. In: Proc international congress complexity and integrated resources management. University, Osnabrück, pp 172-176

Nguyen KA, Stewart RA, Zhang H (2013) An intelligent pattern recognition model to automate the categorisation of residential water end-use events. Environ Model Softw 47:108-127. doi:10.1016/j.envsoft.2013.05.002

O’Connell PE (1980) Real-time hydrological forecasting and control. In: Proc. First International Workshop. Institute of Hydrology, Wallingford, p 264

O’Connell PE, Koutsoyiannis D, Lins HF, Markonis Y, Montanari A, Cohn T (2016) The scientific legacy of Harold Edwin Hurst (1880-1978). Hydrol Sci J. doi:10.1080/02626667.2015.1125998

O'Connell PE, O'Donnell G (2014) Towards modelling flood protection investment as a coupled human and natural system. Hydrol Earth Syst Sci 18(1):155-171. doi:10.5194/hess-18-155-2014

O'Donnell G, O'Connell PE (2017) Human-hydrology systems modeling. In: Singh VP (ed) handbook of applied hydrology, second edition. McGraw Hill professional, pp 153-3-153-14

Olmstead SM (2014) Climate change adaptation and water resource management: a reviewof the literature. Energy Econ 46:500-509. doi:10.1016/j.eneco.2013.09.005 
Pahl-Wostl C (2002) Towards sustainability in the water sector - the importance of human actors and processes of social learning. Aquat Sci 64(4):394-411. doi:10.1007/PL00012594

Pahl-Wostl C (2006) The importance of social learning in restoring the multifunctionality of rivers and floodplains. Ecol Soc 11(1):10

Pahl-Wostl C, Ebenhöh E (2004) Heuristics to characterise human behaviour in agent based models. In: Proc iEMSs international Congress: complexity and integrated resources management, University of Osnabruck, Germany. http://www2.econ.iastate.edu/tesfatsi/HeuristicsHumanBehaviorABM.PahlWostlEbenhoh2004.pdf

Pahl-Wostl C, Hare M (2004) Processes of social learning in integrated resources management. J Community Appl Soc Psychol 14(3):193-206. doi:10.1002/casp.774

Pielke R et al (2009) Climate change: the need to consider human forcings besides greenhouse gases. Eos Trans AGU 90(45):413-413. doi:10.1029/2009EO450008

Pielke R Sr et al (2012) Dealing with complexity and extreme events using a bottom-up, resource-based vulnerability perspective. In: Sharma AS, Bunde A, Dimri VP, Baker DN, (Eds). Extreme events and natural hazards: the complexity perspective, 345-359. Washington, DC: American Geophysical Union.

Plusquellec H (2002) Is the daunting challenge of irrigation achievable? Irrig Drain 51(3):185-198. doi:10.1002/ird.51

Rodolfo KS, Siringan FP (2006) Global sea-level rise is recognised, but flooding from anthropogenic land subsidence is ignored around northern Manila Bay, Philippines. Disasters 30(1):118-139

Rotmans J, Van Asselt M (1996) Integrated assessment: a growing child on its way to maturity. Clim Chang 34(3-4):327-336. doi:10.1007/BF00139296

Schlüter M, Pahl-Wostl C (2007) Mechanisms of resilience in common-pool resource management systems: an agent-based model of water use in a river basin. Ecol Soc 12(2):4

Shamshery P, Wang R-Q, Tran DV, Winter V, Amos G (2017) Modeling the future of irrigation: a parametric description of pressure compensating drip irrigation emitter performance. PLoS One 12(4):e0175241. doi:10.1371/journal.pone.0175241

Shiferaw B et al (2014) Managing vulnerability to drought and enhancing livelihood resilience in sub-Saharan Africa: technological, institutional and policy options. Weather Clim Extremes 3:67-79. doi:10.1016/j. wace.2014.04.004

The Economist (2013) Water: All Dried Up http://www.economist.com/news/china/21587813-northern-chinarunning-out-water-governments-remedies-are-potentially-disastrous-all/comments?page $=5$

UN Water (2013) Water for Food Factsheet http:/www.unwater.org/statistics/thematic-factsheets/en/

UNEP (2012) The UN-water status report on the application of integrated approaches to water resources management. ISBN: 978-92-807-3264-1

Valkering P, Krywkow J, Rotmans J, van der Veen A (2004) Simulating stakeholder support for river management. In: Pahl-Wostl C, Schmidt S, Jakeman T (eds) iEMSs 2004 international Congress: "complexity and integrated resources management". International Environmental Modelling and Software Society, Osnabruck

Verburg P (2006) Simulating feedbacks in land use and land cover change models. Landscape Ecol 21(8):11711183. doi:10.1007/s10980-006-0029-4

2030 Water Resources Group (2009) Charting Our Water Future https://www.2030wrg.org/team/charting-ourwater-future/

2030 Water Resources Group (2012) The Water Resources Group. Background, Impact and the Way Forward. Briefing report prepared for the World Economic Forum Annual Meeting, Davos-Klosters, Switzerland

Wilby RL, Dessai S (2010) Robust adaptation to climate change. Weather 65:180-185. doi:10.1002/wea.543

World Economic Forum (2015) Global Risks Report http://reports.weforum.org/global-risks-2015/

WWAP (United Nations World Water Assessment Programme) (2003) The United Nations world water development report: water for people, water for life. UNESCO, Paris

WWAP (United Nations World Water Assessment Programme) (2006) The United Nations world water development report: water, a shared responsibility. UNESCO, Paris

WWAP (United Nations World Water Assessment Programme) (2009) The United Nations world water development report: water in a changing world. UNESCO, Paris

WWAP (United Nations World Water Assessment Programme) (2012) The United Nations world water development report: managing water under uncertainty and risk. UNESCO, Paris

WWAP (United Nations World Water Assessment Programme) (2014) The United Nations world water development report: water and energy. UNESCO, Paris

WWAP (United Nations World Water Assessment Programme) (2015) The United Nations world water development report: water for a sustainable world. UNESCO, Paris

WWAP (United Nations World Water Assessment Programme) (2016) The United Nations world water development report: water and jobs. UNESCO, Paris

Zellner ML (2008) Embracing complexity and uncertainty: the potential of agent-based modeling for environmental planning and policy. Plann Theory Pract 9(4):437-457. doi:10.1080/14649350802481470 